\title{
PLASTIC MECHANISMS FOR THIN-WALLED COLD-FORMED STEEL MEMBERS IN ECCENTRIC COMPRESSION
}

\author{
Viorel UNGUREANU",**, Maria KOTEŁKO ${ }^{* * *}$, Jan GRUDZIECKI ${ }^{* * *}$ \\ "Department of Steel Structures and Structural Mechanics, Politehnica University of Timisoara, loan Curea 1, 300224 Timisoara, Romania \\ "Laboratory of Steel Structures, Romanian Academy - Timisoara Branch, Mihai Viteazu 24, 300223 Timisoara, Romania \\ **Department of Strength of Materials, Łódź University of Technology, ul. Stefanowskiego 1/15, 90-924 Łódź, Poland \\ viorel.ungureanu@upt.ro, maria.kotelko@p.lodz.pl, jan.grudziecki@p.lodz.pl
}

received 20 October 2015, revised 8 February 2016, accepted 10 February 2016

\begin{abstract}
The Eurocode 3 concerning thin-walled steel members divides members subjected to compression into four classes, considering their ductility. The representatives of the class $\mathrm{C} 4$ are short bars, for which the load-capacity corresponds to the maximum compression stresses less than the yield stress. There are bars prone to local buckling in the elastic range and they do not have a real post-elastic capacity. The failure at ultimate stage of such members, either in compression or bending, always occurs by forming a local plastic mechanism. This fact suggests the possibility to use the local plastic mechanism to characterise the ultimate strength of such members. The present paper is based on previous studies and some latest investigations of the authors, as well as the literature collected data. It represents an attempt to study the plastic mechanisms for members in eccentric compression about minor axis and the evolution of plastic mechanisms, considering several types of lipped channel sections.
\end{abstract}

Key words: Plastic Mechanism, Eccentric Compression

\section{INTRODUCTION}

Eurocode 3 (1993) concerning thin-walled steel members divides members subjected to compression into four classes, considering their ductility. Class $\mathrm{C} 1$ concerns bars, in which global plastic hinges may develop entirely, so that they have a relatively large redundancy of the load-capacity above the fully plastic moment $\mathrm{Mp}$ of the total cross-section. To class $\mathrm{C} 2$ belong bars, for which load-capacity is slightly higher than the fully plastic moment, to class $\mathrm{C} 3$ - bars, for which the load-carrying capacity is situated in the elasto-plastic range. It means, that their loadcapacity is determined by the "first yield criterion" (Mpl).

The code distinguishes also the class $\mathrm{C} 4$ of short bars, for which the load-capacity corresponds to the maximum compression stresses less than the yield stress. There are bars prone to local buckling in the elastic range.

It is very well known that thin-walled cold-formed steel structures (TWCFSS) are usually made of thin-walled members of class 4 sections and they are characterised by a reduced postelastic strength and by a reduced ductility. Since these sections are prematurely prone to local or distortional buckling and they do not have a real post-elastic capacity, a failure of such members is initialized by the local-global interactive buckling of plasticelastic type, not an elastic-elastic one. Thus, the failure at ultimate stage of those members, either in compression or bending, always occurs by forming a local plastic mechanism (Eurocode 3 , 1993) - Fig. 1. This fact suggests the possibility to use the local plastic mechanism analysis to characterise the ultimate strength of such members (their load-carrying capacity). Load-capacity of such members subjected to simple states of loading (pure bending or pure axial compression) is relatively well determined (with high accuracy) both on the basis of the theory of thin-walled structures and in the code specifications. However, determination of the load-capacity of TWCFSS members subjected to combined load, particularly eccentric compression) is still an open question and the code specifications for that case should be improved.

The yield line mechanism analysis has been widely used to study steel members and connections that involve local collapse mechanisms. This method can be used to study post-elastic behaviour, load-carrying capacity, ductility, rotation capacity and energy absorption. A detailed history of yield line mechanism theory has been presented by Zhao (2003). An art review of the application of yield line analysis to cold-formed members has been presented by Hiriyur and Schafer (2004) and Ungureanu et al. (2010) make an inventory, classify and range geometrical and analytical models for the local-plastic mechanisms aiming to characterize the ultimate capacity of some of the most used coldformed steel sections in structural applications.
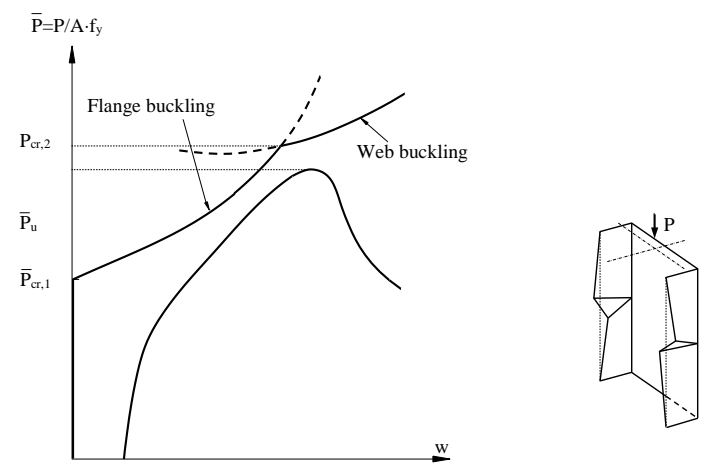

Fig. 1. Structural behavior of short TWCFSS member and exemplary plastic mechanism of failure 


\section{SUBJECT AND OBJECTIVES OF THE ANALYSIS}

Subject of the analysis are TWCFSS members subjected to eccentric compression about minor axis, namely lipped channel section columns (Fig.2.). Positive and negative eccentricities along the symmetry axis are investigated, i.e. $\mathrm{e}=-10 \mathrm{~mm},-5$ $\mathrm{mm},-2 \mathrm{~mm},-1 \mathrm{~mm}, 0 \mathrm{~mm},+1 \mathrm{~mm},+2 \mathrm{~mm},+5 \mathrm{~mm},+10 \mathrm{~mm}$ and $+20 \mathrm{~mm}$.

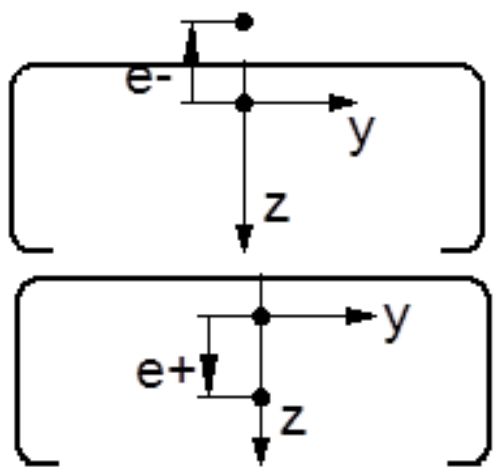

Fig. 2. Lipped channel section with examples of considered eccentricities

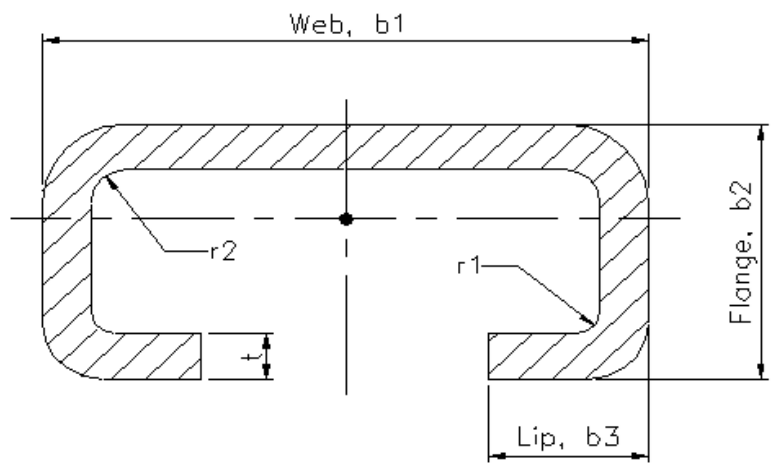

Fig. 3. Lipped channel cross section column dimensions: $b 1=150 \mathrm{~mm}$, b2 $=60 \mathrm{~mm}, \mathrm{~b} 3=20 \mathrm{~mm}, \mathrm{r} 1=1 \mathrm{~mm}, \mathrm{r} 2=1 \mathrm{~mm}, \mathrm{t}=1 \mathrm{~mm}$

Columns of length $L=450 \mathrm{~mm}$ were investigated, made of structural steel of yield stress $\sigma Y=355 \mathrm{MPa}$ and with the cross section shown in Fig. 3.

Present paper is based on previous studies and some latest investigations of authors, as well as the literature collected data. It represents an attempt to study the plastic mechanisms for members in eccentric compression.

The approach is a numerical one (FE analysis), in order to identify the plastic mechanisms of members subjected to eccentric compression about minor axis and the evolution of plastic mechanisms, considering several different eccentricities, which cause either flange or web compression and lead to an evolution of different local plastic mechanisms.

\section{PLASTIC MCHANISMS - STATE OF ART REVIEW}

As was mentioned, the yield line mechanism analysis has been widely used since the 60ties of the XXth Century. Experiments carried out by many researchers on beams or columns built from plate strips, subjected to uniform compression, show, that in such members some simple plastic mechanisms can be distin- guished, which have been termed in Królak (1990) as basic mechanisms. Simultaneously, results of experiments performed, among others, by Murray and Khoo (1981) confirmed, that even a very complex mechanisms can be described as superposition of some simple basic mechanisms. Murray and Khoo (1981)] developed and classified 8 basic plastic mechanisms in plate strips under uniform compression. They also derived for them relations, determining the failure equilibrium path (load versus deflection). These mechanisms and corresponding relations are also described in details in Kotetko (2010).
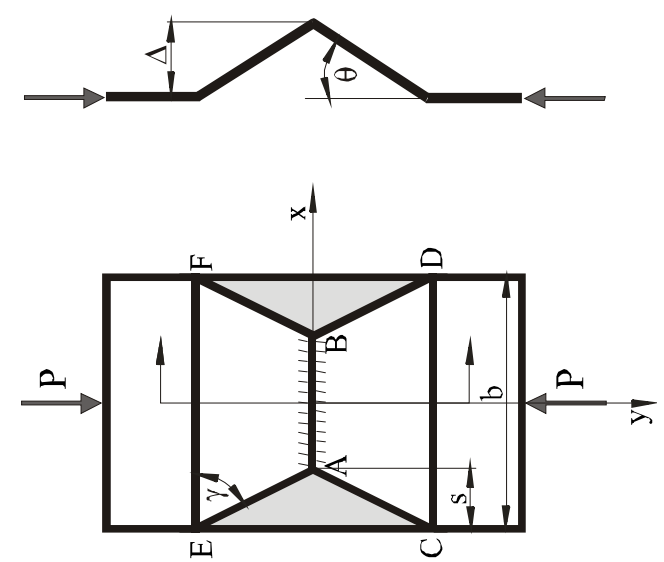

Fig. 4. Local plastic mechanisms in thin plates: - pitched-roof mechanisms, Mahendran (1997)

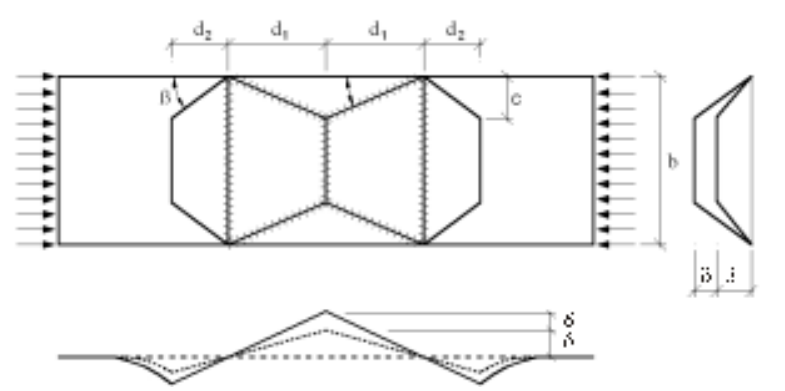

Fig. 5. Local plastic mechanisms in thin plates: - roof mechanism, Ungureanu (2006)

In plates subjected to uniform compression, at symmetrical boundary conditions, which corresponds to the case of column web in compression, a pitched-roof mechanism (Fig. 4) or roof mechanisms (Fig. 5) can develop. The pitched-roof mechanism has been described by some researchers, i.e. Kato (1965), Korol and Sherbourne (1972), Davies et al. (1994) as well as Sin (1985) and Mahendran (1997). Modifications of pitched-roof mechanisms (mainly roof mechanism) were developed by Rondal and Maquoi (1985) and Kragerup (1982). The roof mechanism was also described in details by Ungureanu (2006). All the mechanisms mentioned above, in plate strips and plates under compression are described in details together with corresponding relations for failure equilibrium path (load versus deflection) in Kotełko (2010).

Five plastic mechanisms of failure in channel section columns subjected to axial compression were originally developed by Murray and Khoo (1981). They were also analysed by Mahendran (1997), Dubina and Ungureanu (2002) and Ungureanu and Dubina (2004), who described mechanism CW2 and Rassmussen and Hancock (1991), who analysed mechanisms CF2 and CF3. Mechanisms CW1 and CW2 correspond to the case of the web 
in compression, while mechanisms CF1, CF2 and CF3 - to the case of the flange in compression. In all papers, mentioned above, the yield strip equilibrium method (Kotetko and Mania, 2008; Kotełko, 2010) has been applied.

The equilibrium strip method treats the plastic mechanism as a compatible collection of strips of infinitesimal or unit width parallel to the direction of applied force. On the basis of free-bodydiagram of a separated strip an equilibrium equation is formulated and then, those equations are integrated across walls of the plastic mechanism, in order to obtain simultaneous equilibrium equation for the mechanism as a whole.

An alternative is the energy method (Kotełko and Mania, 2008; Kotełko, 2010). Using the energy method one applies the Principle of Virtual Velocities of the general following form:

$\mathrm{P} \cdot \dot{\delta}=\int_{V} \sigma_{i j} \dot{\varepsilon}_{i j}^{p}(\beta, \chi) d V$,

where: $\delta$-is the global generalized displacement, $\dot{\delta}$ - is the rate of change of the global generalized displacement, $\beta$ - is the vector of kinematical parameters of the plastic mechanisms (kinematically admissible displacements), $\quad \chi \quad$ - is the vector of geometrical parameters of the plastic mechanisms , $\dot{\varepsilon}_{i j}^{p}$ - is the strain rate tensor.

As a result, a load - deformation relation is obtained, the graphical representation of which is a failure equilibrium path. In the case of a plate in compression the Principle (1) takes form

$\delta W_{\text {ext }}=\delta W_{b}+\delta W_{m}$,

where: $W_{b}$ is a bending strain energy, $W_{m}$ - a membrane strain energy.

From equation (2) a current force $P$ in terms of deflection (failure equilibrium path) is obtained. In the case of true mechanisms, eg. CF1 or CF3 (Kotełko, 2010), the bending strain energy takes form:

$W_{p}(\delta)=m_{p} \sum_{i=1}^{n} l_{i}^{\prime} \beta_{i}$,

where: $l_{i}$ - length of $i^{\text {th }}$ yield line, $\beta_{i}$ - angle of rotation at $i^{\text {th }}$ yield line, $\mathrm{m}_{p}$ - fully plastic moment.

After derivation of (3) with respect to rotation angle of the global mechanism, the failure equilibrium path is obtained.
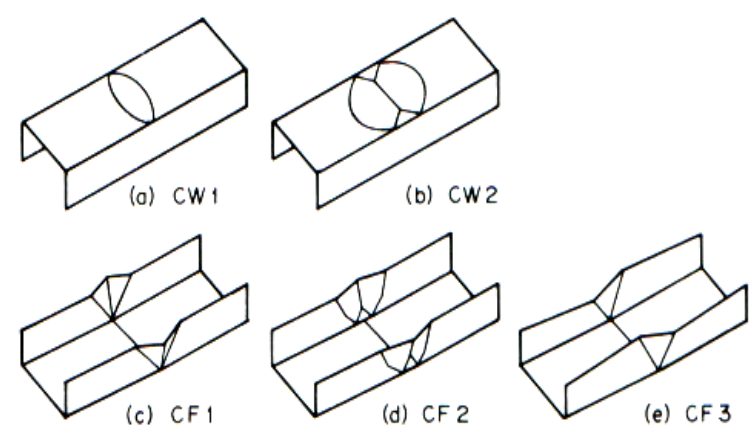

Fig. 6. Basic plastic mechanisms in channel - section columns

\section{IDENTIFICATION OF PLASTIC MECHANISMS IN COLUMNS UNDER ECCENTRIC COMPRESSION}

In order to identify the plastic mechanisms of columns subjected to eccentric compression about minor axis leading to an evolution of different local plastic mechanisms, depending on the position of eccentricity, finite element simulations have been performed for lipped channel section columns described in chapter 2. Failure patterns obtained from FE calculations are shown in Fig. 7 and 8.
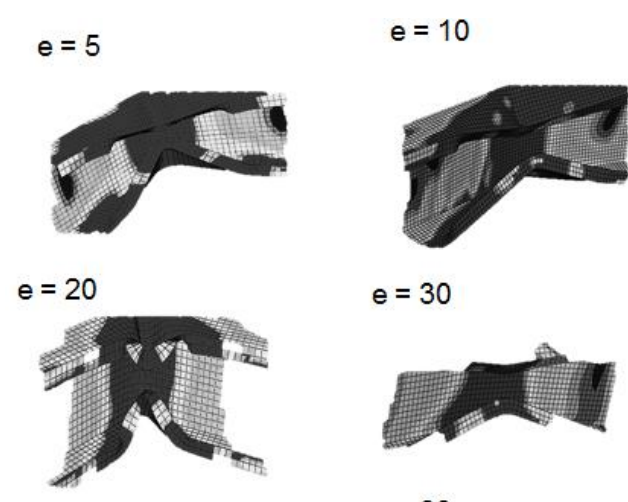

$e=30$

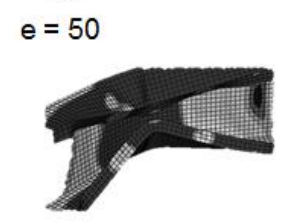

$e=80$

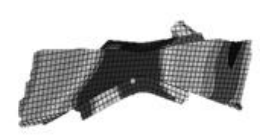

$e=60$

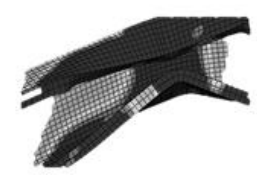

$e=100$

Fig. 7. FE failure patterns for positive eccentricities (flange in compression)
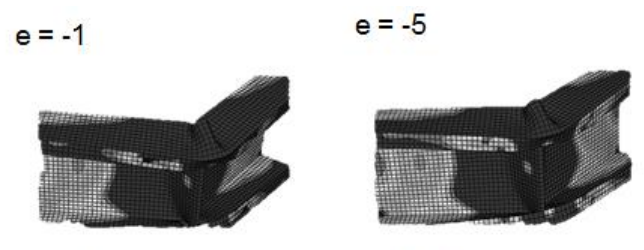

$e=-10$

$e=-30$
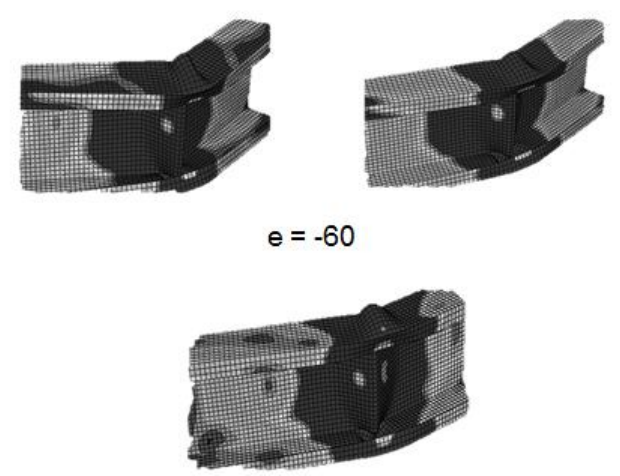

Fig. 8. FE failure patterns for negative eccentricities (web in compression)

On the basis of FE simulations one can state, that a shape of the plastic mechanism strongly depends on the eccentricity value. For positive eccentricities (flange in compression) we observe mechanisms similar to those, shown in Fig. 6. For negative eccentricities (web in compression) one can observe mechanisms similar to mechanisms in plates subjected to uniform compression 
(Fig.5). However, in that case yield lines occur also in flanges and lips, so that the actual mechanism is more complex. Moreover, within those two main cases (flange or web in compression), mechanisms differ, depending on a magnitude of the eccentricity.

According to FE results, four simplified types of plastic mechanisms have been identified. The first (Fig. 9) is a mechanism similar to CF1. It is typical for small positive eccentricities. For larger positive eccentricities the enhanced mechanism CF2 has been identified Fig.10). For small negative eccentricities (web in compression) the V-shaped mechanism was developed (Fig.11), similar to the mechanism for beams in bending (Kotekko, 2010).
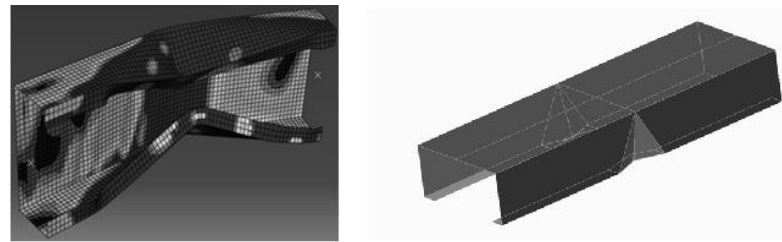

Fig. 9. Enhanced three-hinge mechanism CF1 for positive eccentricities $\mathrm{e}=5,10 \mathrm{~mm}$ (flange in compression)
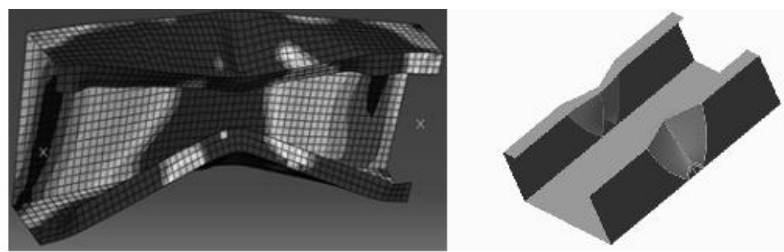

Fig. 10. Enhanced mechanisms CF2 for positive eccentricities $\mathrm{e}=20-100 \mathrm{~mm}$, (flange in compression)
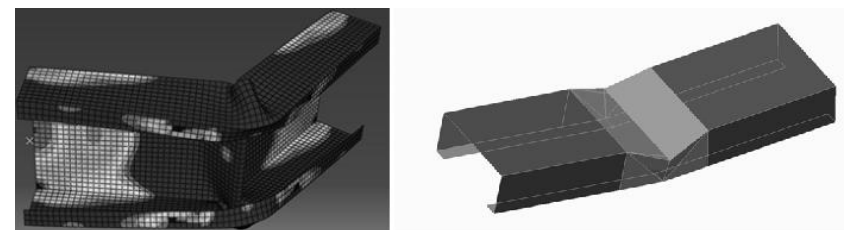

Fig. 11. V-shaped mechanisms for negative eccentricities $e=(-1)-(-10) \mathrm{mm}$
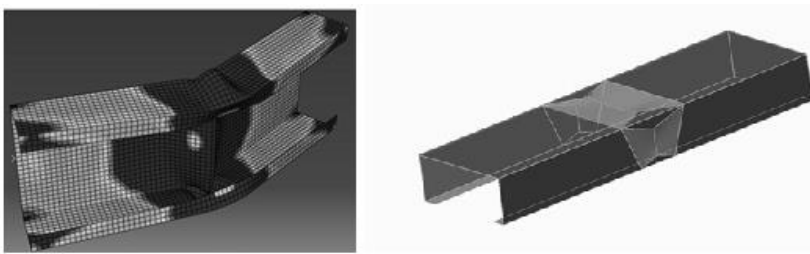

Fig. 12. Pitched-roof mechanism for negative eccentricities $e=(-30)-(-60) \mathrm{mm}$, (web in compression)

For large negative eccentricities the mechanism shown in Fig. 12 has been identified, consisting of the pitched-roof mechanism in the web and additional yield lines and tension fields in the flanges.

Preliminary theoretical calculations based on the mechanisms models shown above have been performed. Selected results of these calculations, compared with FE results are presented in Fig. 13 and 14. In Fig. 13 the failure equilibrium paths obtained for CF1 mechanism are compared with corresponding FE results. The yield line analysis was carried out using the energy method (rel. (3)). Although the mechanism model does not count for yield lines in lips, the agreement with FE results is relatively good.

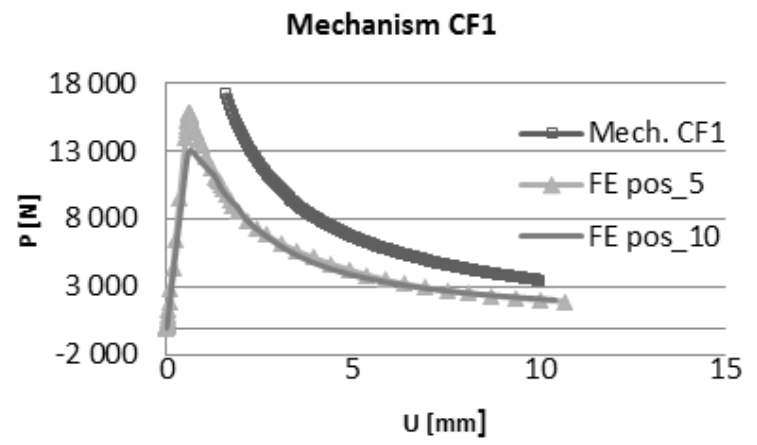

Fig. 13. Comparison of numerical results for small positive eccentricities (flange in compression)

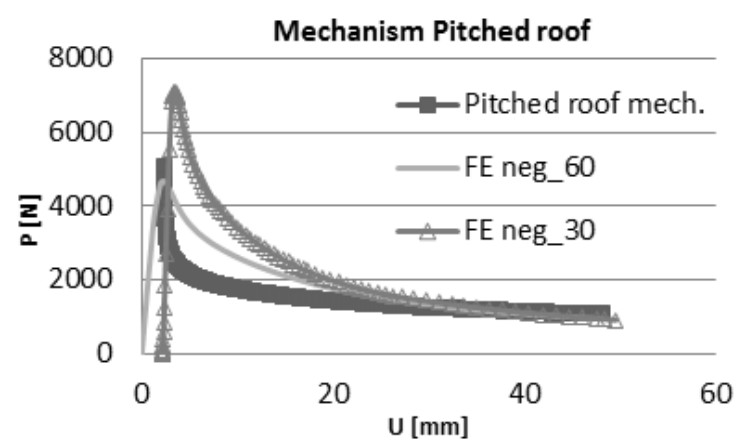

Fig. 14. Comparison of numerical results for large negative eccentricities (web in compression)

The energy method (rel. (2)) was used to obtain failure equilibrium path for mechanism, shown in Fig.12. In relation (2) only the plastic strain energy dissipated in the web (for pitched-roof mechanism) was taken into account. In that case the agreement with FE results is poor, except the last stage of failure.

\section{FINAL REMARKS}

The FE simulation results show, that for short TWCF members subjected to compression or eccentric compression, all elastic phenomena become plastic. Thus, the yield line analysis (plastic mechanism) approach is of aid in the estimation of the load-capacity of such members. However, even if plastic mechanisms are identified for compression and bending separately, in the case of eccentric compression, this is far from a linear superposition of basic mechanisms.

The plastic mechanisms models presented in the paper are the first approximation and should be completed, taking into account tension fields and traveling lines (Kotełko, 2010).

\section{REFERENCES}

1. Davies J.M., Leach P. (1994), First order generalized beam theory, Journal of Construction. Steel research, 39,187-220.

2. Dubina D., Ungureanu V. (2002), Plastic strength of thin-walled members, Sixteenth Int. Specialty Conference on Cold-Formed Steel Structures, Orlando, Florida, 324-332. 
3. Eurocode 1993-1-3: Eurocode 3: Design of steel structures, Part 1-3: General Rules.

4. Hiriyur B.K.J., Schafer B.W. (2004), Yield-line analysis of coldformed steel members, International Journal of Steel Structures, 5(1), 43-54.

5. Kato B. (1965), Buckling strength of plates in the plastic range, International Association of Bridge and Structural Engineering, 25,127-141.

6. Korol R.M., Sherbourne A.N. (1972), Strength prediction of plates in uniaxial compression, Journal of Structural Division, 98, 1965-1986.

7. Kotełko M. (2010), Load-carrying capacity and mechanisms of failure of thin-walled structures, (in Polish), WNT Warszawa.

8. Kotełko M., Mania J.R. (2008), Alternative solution of the problem of load-capacity of thin-walled plated structures, Mechanics and Mechanical Eng., 12(4), 323-336.

9. Kragerup J. (1982), Five notes on plate buckling, Technical University of Denmark, Department of Structural Engineering, Series R, $\mathrm{Nr} 143$.

10. Królak M. [ed.] (1990), Post-buckling and load-capacity of thinwalled girders of flat walls (in Polish), PWN Warszawa-Łódź.

11. Mahendran M. (1997), Local plastic mechanisms in thin steel plates under in-plane compression, Thin-Walled Structure, Elsevier Appl. Sci, 27, 245-261.

12. Murray N.W., Khoo P.S. (1981), Some basic plastic mechanisms in thin-walled steel structures, Int. J. Mech. Sci., 23(12), 703-713.
13. Rassmussen K.J.R., Hancock G.J. (1991), Nonlinear analyses of thin-walled channel-section columns, Thin-Walled Structures, 13(1,2) 145-176.

14. Rondal J., Maquoi R. (1985), Stub-column strength of thin-walled squre and rectangular hollow sections, Thin-Walled Structures, 3 , 15-34.

15. Sin K.W. (1985), The collapse behaviour of thin-walled sections, $\mathrm{PhD}$ Thesis, Dept. of Mechanical Engineering, University of Strathclyde, Glasgow.

16. Ungureanu D.V. (2006), Light steel structures made of cold-formed steel profiles, (in Romanian), Ed. Orizonturi Universitare Timisoara.

17. Ungureanu V., Dubina D. (2004), Post-elastic strength and ductility of cold-formed steel sections, Proc. of Int. Conference on ThinWalled Structures, Loughborough, Thin-Walled Structures, 283-294.

18. Ungureanu V., Kotełko M., Mania R.J., Dubina D. (2010), Plastic mechanisms database for thin walled cold-formed steel members in compression and bending, Thin-Walled Structures, 48(10-11) 818826.

19. Zhao X.-L. (2003), Yield line mechanism analysis of steel members and connections, Prog. Struct. Engng Mater., 5, 252-262.

The work has been presented over the XIVth Symposium on Stability of Structures, Zakopane, Poland, June 2015. 